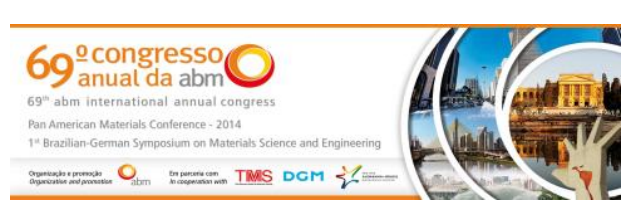

Tema: Gestão de meio ambiente e recuperação e tratamento de rejeitos

\title{
ESTUDO DE ROTA HIDROMETALÚRGICA VISANDO RECUPERAÇÃO DE PRATA A PARTIR DE RESÍDUOS DE PLACAS DE CIRCUITO IMPRESSO*
}

\section{Resumo}

\author{
Ana Paula de Matos Silva \\ Marcos Paulo Kohler Caldas ${ }^{2}$ \\ Lucas Moraes de Sousa ${ }^{3}$ \\ Viviane Tavares de Moraes ${ }^{4}$ \\ Fernando Codelo Nascimento 5 \\ Denise Crocce Romano Espinosa ${ }^{6}$ \\ Jorge Alberto Soares Tenório ${ }^{7}$
}

A recuperação de metais presentes em equipamentos eletroeletrônicos tem atraído interesse em virtude de novas e diferentes tecnologias que visam a reutilização desses elementos químicos em novos processos produtivos. A recuperação de prata de placas de circuito impresso na forma de nanopartículas é uma alternativa para reutilização deste metal nobre. Este trabalho teve como objetivos: recuperar a prata presente em placas de circuito impresso e separar a prata dos demais metais através de rota hidrometalúrgica. A rota hidrometalúrgica para recuperação da prata envolveu a lixiviação em meio ácido a $75^{\circ} \mathrm{C}$, por 18 horas. Após o processo de lixiviação a prata será isolada dos demais metais através de rotas hidrometalúrgicas. A composição do licor lixiviado foi caracterizada por espectrometria de emissão óptica com acoplamento de plasma induzido (ICP-OES). Os resultados indicaram a possibilidade de recuperação de $96,6 \%$ de prata.

Palavras-chave: Reciclagem; Recuperação de prata; Hidrometalurgia.

\section{STUDY HYDROMETALLURGICAL ROUTE AIMING SILVER RECOVERY FROM WASTE PRINTED CIRCUIT BOARDS}

\section{Abstract}

The recovery of metals present in electronics equipment has attracted interest because of new and different technologies to reuse these chemicals in production processes. The silver recovery of printed circuit boards in the form of nanoparticles is an alternative to reuse of the noble metal. This study aimed to: recover the silver present in printed circuit boards and separate silver from other metals by hydrometallurgical route. The hydrometallurgical route for the recovery of silver involved in acid leaching at $75^{\circ} \mathrm{C}$ for 18 hours. After the leaching process the silver will be isolated from other metals by hydrometallurgical routes. The composition of the leached liquor was characterized by optical emission spectrometry with induced coupled plasma (ICP-OES). The results indicated the possibility of $96.6 \%$ recovery of silver.

Keywords: Recycling; Recovery of silver; Hydrometallurgy.

\footnotetext{
Graduando em Tecnologia Ambiental, SENAI Mario Amato, São Bernardo do Campo, SP, Brasil. Doutorando em Engenharia Metalúrgica e Materiais, Escola Politécnica, USP, SP, Brasil. Graduando em Tecnologia Ambiental, SENAI Mario Amato, São Bernardo do Campo, SP, Brasil. Pós Doutoranda em Engenharia Metalúrgica e de Materiais, Escola Politécnica, USP, São Paulo, $S P$, Brasil.

5 , Professor do SENAI Mario Amato, São Bernardo do Campo, SP, Brasil.

Professora Associada, Dept. Eng. Metalúrgica e de Materiais, Escola Politécnica, USP, SP, Brasil.

Professor Titular, Dept. Eng. Metalúrgica e de Materiais, Escola Politécnica, USP, SP, Brasil.
}

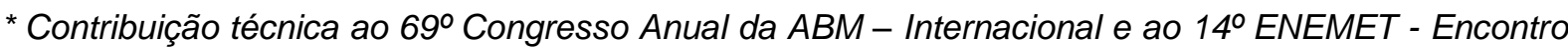
Nacional de Estudantes de Engenharia Metalúrgica, de Materiais e de Minas, 21 a 25 de julho de 2014, São Paulo, SP, Brasil.
} 


\section{INTRODUÇÃO}

Hoje, o consumo desenfreado e o ritmo acelerado da tecnologia trazem como consequência a obsolência programada, obrigando os equipamentos eletroeletrônicos se transformarem em sucatas tecnológicas [1].

A geração crescente deste resíduo tem evoluído para um problema ambiental, onde a preocupação está relacionada à lista de elementos químicos contidos nas sucatas eletroeletrônicas (muitos tóxicos tais como: mercúrio, chumbo, arsênio), e a disposição incorreta desses resíduos [2].

Em grandes quantidades, quando as sucatas são dispostas em aterros sanitários, por exemplo, agravam-se ainda mais a situação, pois com a disposição de elementos químicos que sofrem processo de lixiviação provocado pelos ácidos graxos (provenientes da degradação da matéria-orgânica), pode ocorrer à contaminação do solo e lençóis freáticos [3].

A contaminação pode promover alterações consideráveis nos aspectos físicos, químicos e biológicos, tanto no corpo receptor (solo, água, ar) quanto no metal, ou seja, dependendo das condições ambientais o metal pode sofrer alterações tais como: densidade, toxidade, dentre outras propriedades físico-químicas, proporcionando o desequilíbrio ecológico [4].

Para evitar a disposição incorreta desses resíduos, diversas alternativas vêm sendo aplicadas, umas delas é a minimização dos impactos ambientais através da reciclagem e recuperação dos metais preciosos presentes nas sucatas tecnológicas [5].

Recentemente, recuperar metais preciosos a partir de placas de circuito impresso tornou-se algo de interesse das empresas, isso porque os metais preciosos e o cobre representam mais de $95 \%$ do valor total intrínseco da placa. Para empresa é a oportunidade de praticar o desenvolvimento sustentável adquirindo matéria-prima a partir de um resíduo [6].

O desenvolvimento sustentável é um dos alavanques para a prática de reciclagem de equipamento eletroeletrônico obsoleto, três dos desafios da gestão de Resíduos de equipamentos eletroeletrônicos (REEE) é exatamente o tripé da sustentabilidade (preservação do meio ambiente, reuso e remanufatura de REEE e inclusão dos catadores gerando emprego e renda, e também uma forma da empresa fazer marketing ambiental) [7].

Esse artigo aborda a recuperação da prata presente nas de placas de circuito impresso, no qual apresenta o passo a passo do processo hidrometalúrgico. Tendo como principal objetivo a alternativa de recuperar prata presente em resíduo eletroeletrônico obsoleto, minimizando a extração de recursos naturais.

A falta de tecnologia no mercado e a maximação de resíduo eletroeletrônico contendo metais preciosos foram à razão pela qual esse artigo foi desenvolvido.

No processo hidrometalúrgico, o fator tempo de reação, temperatura e concentração do ácido foi fundamental para a eficiência de dissolução prata. Outro fator que otimizou o estudo foi à eliminação da técnica de separação magnética para retirada dos materiais ferromagnéticos [8].

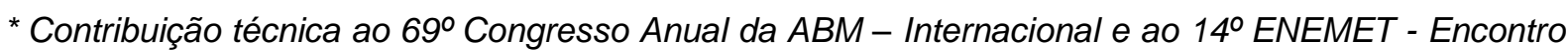
Nacional de Estudantes de Engenharia Metalúrgica, de Materiais e de Minas, 21 a 25 de julho de 2014, São Paulo, SP, Brasil.
} 


\section{MATERIAIS E MÉTODOS}

\subsection{Processamento Manual}

Para desenvolvimento deste estudo foram selecionadas placas de circuito impresso, provenientes de computadores obsoletos. Inicialmente as placas de circuito impresso foram pesadas numa balança semi analítica.

\subsection{Processamento Físico}

No processamento físico, foi utilizado o moinho de facas com grelha de $9 \mathrm{~mm}$ seguido de moagem em moinho de martelos com grelha de $2 \mathrm{~mm}$, tendo como finalidade a redução do tamanho, aumento da área superficial e liberação dos materiais das placas de circuito impresso.

\subsection{Caracterização}

Através da caracterização identificaram-se quais metais contidos nas placas de circuito impresso assim como sua quantificação, utilizou-se para tal experimento digestão em água régia; perda ao fogo e analise química.

\subsubsection{Digestão em água régia}

Da amostra obtida no processamento físico, $5 \mathrm{~g}$ foi solubilizada em $100 \mathrm{ml}$ de água régia, durante 24 horas, sem aquecimento.

Após digestão a amostra foi filtrada em papel de filtro quantitativo de filtragem rápida; nesse procedimento obteve-se: o licor, no qual tem-se água-régia e metais solubilizados e a amostra sólida pós-digestão, que corresponde aos sólidos não solúveis, isto é, materiais cerâmicos e poliméricos.

\subsubsection{Ensaio de perda ao fogo}

O ensaio de perda ao fogo foi utilizado para determinação de componentes orgânicos e inorgânicos.

Nesse procedimento foi colocada uma fração da amostra em navículas de porcelana, pesou-se em uma balança analítica e em seguida as amostras foram levadas a um forno tipo mufla a $800^{\circ} \mathrm{C}$ por cerca de 1 hora. Após 1 hora, a amostra foi retirada e pesada novamente para cálculo de perda de massa.

\subsubsection{Análise química}

O licor obtido na digestão foi enviado para análise química. Utilizou-se a técnica de espectrometria de emissão óptica com acoplamento de plasma induzido (ICP-OES). Os metais analisados foram: $\mathrm{Ag}, \mathrm{Al}, \mathrm{Au}, \mathrm{Cu}, \mathrm{Fe}, \mathrm{Ni}, \mathrm{Sn}, \mathrm{Zn}$.

\subsection{Processamento Hidrometalúrgico}

Após a identificação dos metais presentes na placa de circuito impresso, foi possível o processamento hidrometalúrgico, dividiu-se em três etapas: lixiviação com ácido sulfúrico; lixiviação com ácido sulfúrico em meio oxidante e lixiviação em ácido nitrico.

Após cada lixiviação foi retirada alíquota de $50 \mathrm{ml}$ do licor e enviado para análise quimica de ICP-OES.

* Contribuição técnica ao 69 Congresso Anual da ABM - Internacional e ao 14ํㅡㄹ ENEMET - Encontro Nacional de Estudantes de Engenharia Metalúrgica, de Materiais e de Minas, 21 a 25 de julho de 2014, São Paulo, SP, Brasil. 


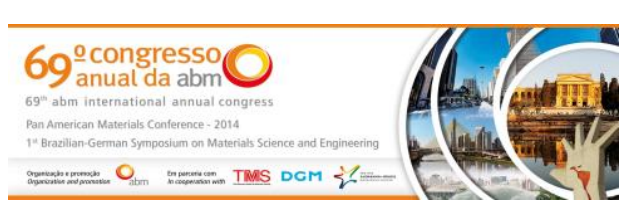

Durante os processos de lixiviação o ensaio se manteve sob agitação mecânica em sistema fechado.

\subsubsection{Lixiviação ácida}

A amostra quarteada de aproximadamente $35 \mathrm{~g}$ foi imersa em $360 \mathrm{~mL}$ de ácido sulfúrico $1 \mathrm{M}, 75^{\circ} \mathrm{C}$ por 18 horas. O licor lixiviado foi filtrado num papel de filtro quantitativo de filtragem rápida.

O filtrado foi armazenado em um tubo de ensaio e o material retido no papel de filtro foi lavado com água deionizada, em seguida colocado na estufa durante 24 horas a $60^{\circ} \mathrm{C}$ para secagem e pesagem do resíduo. A Figura 1 mostra o esquema de lixiviação.

Figura 1: Processamento hidrometalúrgico - Lixiviação ácida

\subsubsection{Lixiviação ácida em meio oxidante}

O resíduo obtido da lixiviação ácida foi submetido á lixiviação ácida em meio oxidante, com ácido sulfúrico e peróxido de hidrogênio, para lixiviação do cobre.

Durante a lixiviação foi adicionado $10 \mathrm{~mL}$ de peróxido de hidrogênio 130 volumes a cada 30 minutos até completar 6 horas de lixiviação a $75^{\circ} \mathrm{C}$. Após lixiviação o material em contato com o peróxido de hidrogênio foi filtrado num papel de filtro quantitativo de filtragem rápida.

O filtrado foi armazenado em um tubo de ensaio e o material retido no papel de filtro foi lavado com água deionizada, em seguida colocado na estufa durante 24 horas a $60^{\circ} \mathrm{C}$ para secagem e pesagem do resíduo.

\subsubsection{Lixiviação com ácido nítrico}

Com o intuito de recuperar mais de $95 \%$ do metal (prata), o resíduo proveniente da lixiviação com peróxido de hidrogênio foi submetido à lixiviação com ácido nítrico $10 \mathrm{M}$, foi utilizado uma relação 1: 20 (S/L) á temperatura ambiente durante 2 horas.

\section{RESULTADOS E DISCUSSÃO}

\subsection{Processamento Manual}

Foram selecionadas cerca de $5 \mathrm{~kg}$ de placas de circuito impresso lead free. $\mathrm{O}$ modelo de $\mathrm{PCl}$ de placa mãe está mostrado na Figura 2.

\footnotetext{
* Contribuição técnica ao $69^{\circ}$ Congresso Anual da ABM - Internacional e ao 14ํㅡㄹ ENEMET - Encontro Nacional de Estudantes de Engenharia Metalúrgica, de Materiais e de Minas, 21 a 25 de julho de 2014, São Paulo, SP, Brasil.
} 


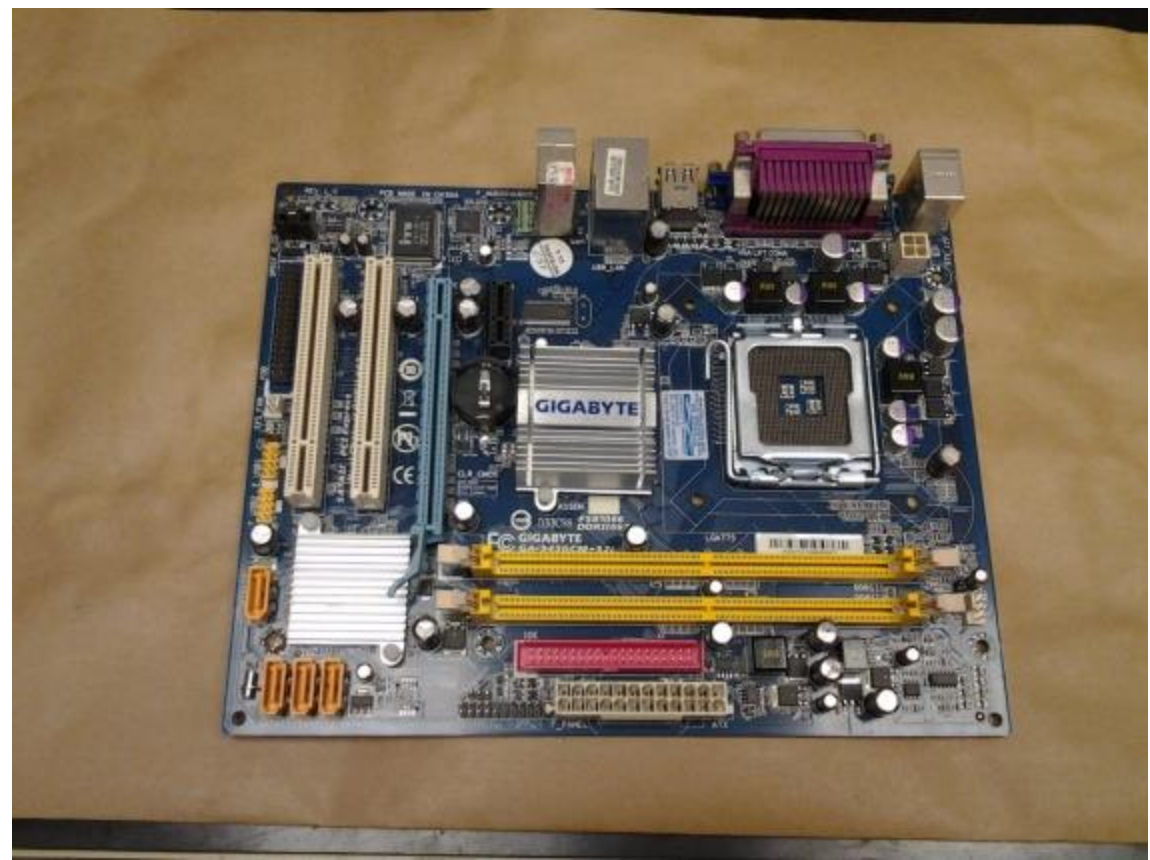

Figura 2: Placa de circuito impresso

\subsection{Processamento Físico}

Após o processo manual, cerca de $5 \mathrm{~kg}$ foram levadas para o moinho de facas seguido do moinho de martelo. A porcentagem de perda de massa no processamento físico foi de $1,16 \%$ da massa total.

\subsubsection{Digestão em água régia}

O balanço de massa realizado na digestão em água régia, mostra que cerca de $35,5 \%$ da placa de circuito impresso foi lixiviada, o que representa a fração de metais.

\subsubsection{Ensaio de Perda ao Fogo}

Associando os resultados de digestão em água régia e perda ao fogo foi possível determinar que as placas de circuito impresso são formadas por $25,8 \%$ material polimérico; $38,7 \%$ material cerâmico e $35,5 \%$ de metais.

\subsubsection{Análise Química}

$\mathrm{Na}$ análise química obtiveram-se as porcentagens dos elementos, como mostrado na tabela 1.

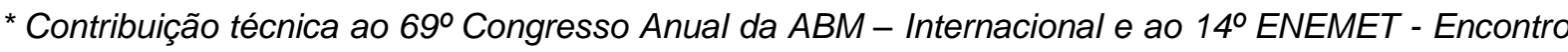
Nacional de Estudantes de Engenharia Metalúrgica, de Materiais e de Minas, 21 a 25 de julho de 2014, São Paulo, SP, Brasil.
} 
Tabela 1: Porcentagem dos metais presentes na placa de circuito impresso

\begin{tabular}{l|r}
\hline METAL & PORCENTAGEM (\%) \\
\hline $\mathrm{Ag}$ & 0,045 \\
\hline $\mathrm{Al}$ & 2,66 \\
\hline $\mathrm{Au}$ & 0,002 \\
\hline $\mathrm{Cu}$ & 19,42 \\
\hline $\mathrm{Fe}$ & 8,34 \\
\hline $\mathrm{Ni}$ & 0,27 \\
\hline $\mathrm{Sn}$ & 1,99 \\
\hline Zn & 2,55 \\
\hline Outros $(\mathrm{Ba}, \mathrm{Ca}, \mathrm{Mg}, \mathrm{Pb})$ & 0,23 \\
\hline Total & 35,5 \\
\hline
\end{tabular}

\subsection{Processamento Hidrometálurgico}

Com a sequencia de lixiviação: com ácido sulfúrico; com ácido sulfúrico em meio oxidante e ácido nitrico, foi possível realizar análise quantitativa do licor para caracterização dos metais. O resultado das porcentagens de extração de cada metal em cada etapa do processo hidrometalúrgico estão descritas na Tabela 2.

Tabela 2: Porcentagem de extração de cada metal após rota hidrometalúrgica

\begin{tabular}{c|c|c|c|c}
\hline METAL & $\begin{array}{c}\text { LIXIVIAÇÃO } \\
\text { ÁCIDA (\%) }\end{array}$ & $\begin{array}{c}\text { LIXIVIAÇÃO } \\
\text { ÁCIDA EM MEIO } \\
\text { OXIDANTE (\%) }\end{array}$ & $\begin{array}{c}\text { LIXIVIAÇÃO } \\
\text { COM ÁCIDO } \\
\text { NÍTRICO (\%) }\end{array}$ & $\begin{array}{c}\text { TOTAL DE } \\
\text { EXTRAÇÃO } \\
\text { DOS METAIS } \\
(\%)\end{array}$ \\
\hline $\mathrm{Ag}$ & 0 & 41 & 55,6 & 96,6 \\
\hline $\mathrm{Al}$ & 74,7 & 17,9 & 1,2 & 93,8 \\
\hline $\mathrm{Au}$ & 0 & 0 & 0 & 0 \\
\hline $\mathrm{Cu}$ & 0 & 62,7 & 37,3 & 100 \\
\hline $\mathrm{Fe}$ & 36,1 & 63,9 & 0 & 100 \\
\hline $\mathrm{Ni}$ & 6,4 & 88 & 5,6 & 100 \\
\hline $\mathrm{Sn}$ & 29,5 & 2,1 & 2,6 & 84,2 \\
\hline $\mathrm{Zn}$ & 7,1 & 66,8 & 13,7 & 1,083 \\
\hline Outros & 0,603 & 0,31 & 0,17 & \\
\hline
\end{tabular}

\subsubsection{Lixiviação Ácida}

Na lixiviação ácida foi possível extrair 7,0\% de metais em ácido sulfúrico $1 \mathrm{M}$. Com os valores obtidos pela analise em ICP-OES do licor lixiviado foi possível verificar que a prata não é extraída nesta etapa, o que já era esperado.

Nesta etapa espera-se extrair principalmente $74,7 \%$ de $\mathrm{Al}, 36,1 \%$ de $\mathrm{Fe}, 6,4 \%$ de $\mathrm{Ni}$, $29,5 \%$ de Sn e $7,1 \%$ de $Z n$.

Cobre só é retirado em ácido forte e em meio oxidante, por esta razão não se obteve lixiviação do cobre. Para a extração deste metal utiliza-se a próxima lixiviação (acido sulfúrico em meio oxidante).

* Contribuição técnica ao 69 Congresso Anual da ABM - Internacional e ao 14ํㅡㄹ ENEMET - Encontro Nacional de Estudantes de Engenharia Metalúrgica, de Materiais e de Minas, 21 a 25 de julho de 2014, São Paulo, SP, Brasil. 


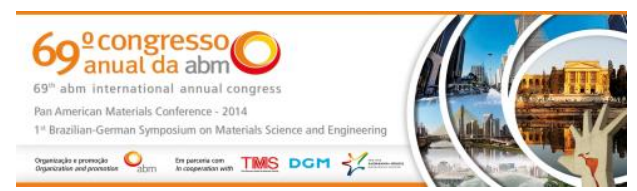

A lixiviação de $\mathrm{Ni}$ e $\mathrm{Zn}$ não foi de $100 \%$ como o esperado, pois os mesmos devem formar algum tipo de liga metálica com o cobre impossibilitando a sua lixiviação individual, isto é, somente quando o cobre for $100 \%$ lixiviado o zinco e níquel também serão.

O Sn, como já esperado, deve ter baixa lixiviação em toda a rota hidrometalurigica, pois os compostos formados durante a lixiviação formam substancias de estanho parcialmente insolúveis, como o sulfato de estanho.

Como a lixiviação total de ferro não foi atingida na lixiviação ácida é possível que durante a lixiviação em meio oxidante o ferro provoque um processo de cementação do cobre impedindo sua extração total na etapa de lixiviação em meio oxidante [11].

\subsubsection{Lixiviação ácida em meio oxidante}

O resíduo proveniente da lixiviação ácida foi imerso em ácido sulfúrico com adição de peróxido de hidrogênio, onde $21,5 \%$ de metais solubilizaram, entretanto após analise em ICP-OES identificou-se $0,005 \mathrm{~g}$ de prata solúvel, $41 \%$ extração do total de prata. A extração de prata nesta etapa pode ter ocorrido devido ao aumento de potencial gerado em meio oxidante, atingindo sua faixa de solubilização.

Nesta etapa espera-se extrair principalmente $17,9 \%$ de $\mathrm{Al}, 62,7 \% \mathrm{Cu}, 63,9 \%$ de $\mathrm{Fe}$, $88 \%$ de $\mathrm{Ni}, 2,1 \%$ de $\mathrm{Sn}$ e $66,8 \%$ de $\mathrm{Zn}$.

Como o ferro não foi extraido $100 \%$ na lixiviação acida ele interferiu no processo de extração do cobre, devido o processo de cementação [11].

\subsubsection{Lixiviação com ácido nítrico}

Nesta etapa de lixiviação ocorreu 7,9\% de extração dos metais.

Somando os valores das três lixiviações observa-se que de $0,045 \%$ de prata presente na placa de circuito impresso $0,043 \%$ foi extraído. No entanto dos $0,045 \%$ de prata 55,6\% foi extraída na lixiviação com ácido nítrico $10 \mathrm{M}$ e $41 \%$ com ácido sulfúrico em meio oxidante.

Com os resultados pode-se concluir que a prata é parcialmente solúvel em ácido sulfúrico em meio oxidante e ácido nítrico, resultando em $96,6 \%$ de extração de prata.

Como as lixiviações ácida e em meio oxidante não totalizaram a extração dos metais $\mathrm{Al}, \mathrm{Ni}, \mathrm{Sn}$ e $\mathrm{Zn}$, isso porque não se obteve $100 \%$ da extração destes metais nas etapas que antecedem a lixiviação com ácido nítrico, deve-se aumentar o tempo de reação das lixiviações ácida e em meio oxidante a fim de promover maior seletividade para a recuperação de prata.

\section{CONCLUSÃO}

Os resultados obtidos neste trabalho permitem concluir que a recuperação de $96,6 \%$ da prata, no processamento de placas de circuito impresso proveniente de computadores obsoletos, trouxe vantagens considerando que processos como: separação magnética, separação eletrostática dentre outros, não foram necessárias, exatamente porque o metal em estudo é encontrado em pequenas concentrações nos resíduos eletroeletrônicos. Pode-se concluir também que a recuperação de metais preciosos, no caso a prata, é viável, pois a mesma possui um grande valor agregado viabilizando a reciclagem de equipamentos eletroeletrônicos.

A rota hidrometalurgica para a extração de prata a partir de placas de circuito impresso é: ácido sulfúrico $1 \mathrm{M}, 75^{\circ} \mathrm{C}$, acima de $18 \mathrm{~h}$; seguida de ácido sulfúrico em meio oxidante $1 \mathrm{M}$, acima de $6 \mathrm{~h}$; ácido nítrico $10 \mathrm{M}, 2 \mathrm{~h}$.

\footnotetext{
* Contribuição técnica ao $69^{\circ}$ Congresso Anual da ABM - Internacional e ao 14ํㅡㄹ ENEMET - Encontro Nacional de Estudantes de Engenharia Metalúrgica, de Materiais e de Minas, 21 a 25 de julho de 2014, São Paulo, SP, Brasil.
} 


\section{Agradecimentos}

Instituto Federal do Espírito Santo - Campus Serra

\section{CAPES}

Rede Nanobiotec

Faculdade SENAI de Tecnologia Ambiental

Instituto de Estudos Avançados em Gestão Ambiental - IGAMBIENTAL.

Departamento de Engenharia Metalúrgica e de Materiais - Escola Politécnica Universidade de São Paulo.

\section{REFERÊNCIAS}

1 SIREE. III Seminário Internacional sobre Resíduos de Equipamentos Eletroeletrônicos: Cidades Sustentáveis e Experiências Inovadoras na Gestão de Resíduos de Equipamentos Eletroeletrônicos. Recife: Massangana, fev. 2013.

2 Moraes VT. Recuperação de metais a partir do processamento mecânico e hidrometalúrgico de placas de circuito impresso de celulares obsoletos. Tese (Doutorado) - Curso de Engenharia Metalúrgica e de Materiais, Escola Politécnica da Universidade de São Paulo, São Paulo, 2011.

3 Luppi TVS. Recuperação de prata a partir de radiografias. 2008. 70 f. Monografia (Especialização) - Curso de Tecnologia em Processos Ambientais, Faculdade SENAI de Tecnologia Ambiental, São Bernardo do Campo, 2008.

4 Furtado JGC. Estudo de impactos ambientais causados por metais pesados em água do mar na baía de São Marcos: CORRELAÇÕES E NÍVEIS BACKGROUND. 2007. 74 f. Dissertação (Mestrado) - Curso de Pós Graduação em Química, Departamento de Centro de Ciências Exatas de Natureza, Universidade Federal da Paraíba, João Pessoa, 2007.

5 Domingues TCG. Teor de metais pesados em solo contaminado com resíduo de sucata metálica, em função de sua acidificação. 2009. 86 f. Dissertação (Mestrado) - Curso de Pós Graduação Agricultura Tropical e Subtropical, Instituto Agronômico, Campinas, 2009.

6 Rashchi F, Naseri NJ. Recovery of ultra fine grained silver and copper from PC Board scrapts. Separation And Purification Technology, Tehran, 2012: 92: 36-42: p.1-42.

7 Ewald MR. ABNT NBR 16156: 2013 Resíduos de Equipamentos Eletroeletrônicos Requisitos para atividade de manufatura reversa. 2014 [Acesso em: 15 mar. 2014]. Disponível em:

<http://www.abnt.org.br/imagens/eventos_comunicacao/Lancamento_ABNTNBR_1615 6.pdf>.

8 Yamane LH. Recuperação de metais de placas de circuito impresso de computadores obsoletos através de processo biohidrometalurgico. $125 \mathrm{f}$. Tese (Doutorado) - Curso de Engenharia, Escola Politécnica da Universidade de São Paulo, São Paulo, 2012.

9 Jackson E. Hydrometallurgical extraction and reclamation. Ellis Hoorwood Limited, New York, 1986, p. 29-39,.

\section{BIBLIOGRAFIA}

1 Park YJ, Fray DJ. Recovery of high purity precious metals from printed circuit boards. Elsevier. Reino Unido, p. 1152-1158. 21 set. 2008.

2 Ministério do Meio Ambiente. Política Nacional de Resíduos Sólidos. 2013 [acesso em 12/12/2013]. Disponível em:

http://www.mma.gov.br/sitio/index.php?ido=ascom.noticiaMMA\&idEstrutura=8\&codigo60 21.

\footnotetext{
* Contribuição técnica ao $69^{\circ}$ Congresso Anual da ABM - Internacional e ao 14ํㅡㄹ ENEMET - Encontro Nacional de Estudantes de Engenharia Metalúrgica, de Materiais e de Minas, 21 a 25 de julho de 2014, São Paulo, SP, Brasil.
} 